\title{
Study on Dynamic Mechanical Properties and Microstructure of Epoxy Asphalt
}

\author{
Zhe DONG ${ }^{1, a,{ }^{*}}$, Li-Ping $\mathrm{LI}^{2, \mathrm{~b}}$ \\ ${ }^{1}$ Transportation Engineering Bureau of Tongliao City, Inner Mongolia \\ ${ }^{2}$ Wuhan University of Technology,Wuhan \\ aemail: 398089579@qq.com, bemail: lipingli2014@foxmail.com \\ *Corresponding author: Zhe DONG, lipingli2014@foxmail.com
}

Keywords: Epoxy asphalt; Dynamic mechanical property; Morphology; Curing

\begin{abstract}
The morphology and dynamic mechanical properties of epoxy modified asphalt(EMB) were studied using dynamic mechanical analyzer (DMA) and fluorescent microscopy (FM). DMA results showed that dynamic modulus and storage modulus reached a maximum value when $5 \mathrm{wt} \%$ epoxy resins were added. However, the dynamic modulus and storage modulus decreased, when the contents of epoxy resin are more than 5\%. The FM analysis showed that epoxy asphalt has finished basically after the curing for 4 hours and has formed the epoxy network structure. The layered hydrotalcite and rubber powder are distributed evenly in the epoxy asphalt and form a stable continuous phase, when the epoxy resin content is more than $3 \%$.
\end{abstract}

\section{Introduction}

The Epoxy modified bitumen(EMB) was first used by the Shell Company in the 1950s to improve the corrosion resistance of jet fuel and high-temperature airflow in the airfield[1]. And it was widely used as the ideal road building material of steel deck pavement, pavement wearing surface, and overload traffic pavement. Deck paving of the TianJin bascule bridge in China used lightweight epoxy asphalt mixture to replace part of the basalt aggregate in an epoxy asphalt mixture with lightweight aggregate.

Epoxy resin containing a unique epoxy group, polar hydroxyl group, ether linkage, other active groups, and polar groups, which has many excellent properties, is an excellent asphalt additive[2]. Engineering practice indicates that EMB has better comprehensive performance than other modified asphalt, such as adhesion, tensile strength, and breaking elongation[3]. Epoxy asphalt concrete has the high strength, high stiffness, fatigue resistance, corrosion resistance, and other excellent properties when epoxy resin asphalt was used as binder[4]. Xiao et al[5] used EMB to prepare tar-containing anti-skid surfaces and studied the road performance of EMB. Results indicated that the epoxy asphalt concrete has the excellent high-temperature resistance and the adhesion property at the interface is much higher than the adhesion in the asphalt mixture. Owing to its brittleness of epoxy bitumen, lv et al[6] investigated that rubber modified epoxy asphalt improve the toughness of epoxy bitumen. In order to improving the anti-ultraviolet aging performance, layered hydrotalcite(LDHs) were added as an additive in our experiments.

According to the results of DMA test, it was easy to evaluate the pavement performance of asphalt and predict the service life. Many researchers used dynamic shear rheometer to study dynamic mechanical property of epoxy asphalt. Çubuk et al[7]used dynamic shear rheometer to study dynamic mechanical property of EMB. Appreciable decreasing in the formation of rutting and cracking of EMB may be obtained. However, few literatures were found to use dynamic mechanical analysis to investigate dynamic mechanical property of EMB.

Zhou et al[8] used the first principles and the molecular dynamics simulation to investigate the molecular movement and the structural change of EMB during its curing process. Brule et al[9] found that the phase morphology of two interlocked continuous phases was an ideal microstructure for polymer modified asphalt, and the optimum polymer content was determined based on the formation of the critical network between asphalt and polymer[9, 10]. This paper used dynamic 
mechanical analysis to investigate dynamic mechanical property of EMB. Different contents of epoxy resins were added into asphalt with 60/70 penetration grade to get the optimum dosage of additives. Besides, the effect of different load modes on dynamic mechanical property for epoxy asphalt were studied. Based on these results, the optical load modes will be defined. According to the characteristic of material, using fluorescent microscopy to observe the effect of different method of the preparation and different curing time on the microstructure of epoxy asphalt.

\section{Materials and Experiment}

\subsection{The preparation of epoxy asphalt}

One asphalt with 60/70 penetration grade was offered by Sangyong Company, China. A two-component bisphenol-A type epoxy resin used in this study was produced by Wuhan XingZhengYuan Co. Ltd. Properties of the epoxy resin used are given in Table 1

Table 1 Fundamental properties of epoxy resin

\begin{tabular}{cccccc}
\hline Sample & Appearance & $\begin{array}{c}\text { Peel } \\
\text { strength }\end{array}$ & $\begin{array}{c}\text { Tensile } \\
\text { strength }\end{array}$ & Volume ratio & Curing time \\
\hline epoxy resin & viscous liquid & $22 \mathrm{MPa}$ & $>20 \mathrm{MPa}$ & $1: 1$ & $3-4 \mathrm{~h}$ \\
\hline
\end{tabular}

$400 \mathrm{~g}$ base asphalt was firstly heated to $135^{\circ} \mathrm{C}$. A high shear mixer was dipped into the can and set to about $600 \mathrm{rpm}$. After this system has kept in this temperature for a few minutes, $4 \mathrm{wt} \%$ of LDHs and $20 \mathrm{wt} \%$ of rubber particles were then added into the asphalt and stirred for $1 \mathrm{~h}$ at a speed of $600 \mathrm{rpm}$. Next, a high shear mixer was used to mix the composite at a speed of 5,000 rpm for another $1 \mathrm{~h}$. Then, B component of epoxy was added and mixed with the composite for 15 min at the same speed. At last, a component of epoxy resin was added in the composite and stirred for 15 min. In the epoxy, the ratio of A to B component by weight was $1: 1$. The total content of epoxy to the weight of bitumen was set at 1, 3, 5, 10, 15 and $20 \%$. It meant that four EMB binders were prepared. These binders' experimentally rheological properties were given in Table 2.

Table 2 Experimentally rheological properties of EMB binder

\begin{tabular}{llccc}
\hline Sample & Composition (wt\%) & $\begin{array}{c}\text { Softening } \\
\text { point, }\left[{ }^{\circ} \mathrm{C}\right]\end{array}$ & $\begin{array}{c}\text { Penetration at } \\
25^{\circ} \mathrm{C},[\mathrm{dmm}]\end{array}$ & $\begin{array}{c}\text { Ductility at } \\
5{ }^{\circ} \mathrm{C}, \%\end{array}$ \\
1 & Base bitumen(B) & 48.8 & 61.8 & 15 \\
2 & EMB1\% & 56.4 & 62.3 & 42 \\
3 & EMB3\% & 68.2 & 63.8 & 57 \\
4 & EMB5\% & 80.8 & 65.6 & 68 \\
5 & EMB10\% & 91.5 & 58.0 & 79 \\
6 & EMB15\% & $>100$ & 53.2 & 88 \\
7 & EMB20\% & $>100$ & 46.2 & 102 \\
\hline
\end{tabular}

\subsection{Test methods}

Dynamic mechanical analysis was carried out using a dynamic mechanical analyzer(EPLEXOR $150 \mathrm{~N})$. Epoxy asphalt specimens of $30 \mathrm{~mm}$ in length, $10 \mathrm{~mm}$ in width and $3 \mathrm{~mm}$ in thickness were made. And the specimens were put into fridge to keep the shape-unchanged. Temperature sweeps were applied over the range from $-80^{\circ} \mathrm{C}$ to $30^{\circ} \mathrm{C}$ at a heating rate of $2^{\circ} \mathrm{C} / \mathrm{min}$ with a frequency of $10 \mathrm{~Hz}$; The specimens were kept under a liquid nitrogen atmosphere during the testing.

Optical microscopy was used to investigate the morphology of EMB and pressing and solvent method was used to prepare the sample. The morphology of epoxy asphalt was carried out using a Fluorescent microscopy(FM)(YS-100) that was made by Yuyangfan company, NanJing. Pressing method is that using a small drop of the bitumen was placed between two heated microscope glass slides and press to form a thin film[11]. Solvent method is that low-viscosity solution were prepared using little bitumen and trichloroethane, then, drop a drop of bitumen into the microscope glass slide. 


\section{Results and discussion}

\subsection{Storage modulus $E^{\prime}$}

The storage modulus $E^{\prime}$ represents the stiffness of a viscoelastic material and is proportional to the energy stored during a load cycle[12]. The variation of storage modulus as a function of temperature of EMB is given in Fig.1. Although the storage modulus of epoxy asphalt decreases with the increase of temperature. In the low temperature zone, the storage modulus $\mathrm{E}^{\prime}$ decreases slowly with the increase of temperature, and the storage modul us of epoxy asphalt can reach 3000MPa. It showed that there is a temperature point, below this point, the decrease amplitude is very large with the increase of temperature. The storage modulus reduced significantly and decreased from $3000 \mathrm{MPa}$ to $800 \mathrm{MPa}$. In the high temperature zone, the storage modulus E' changed obviously as the temperature changed. There are three kind of mechanical state, which contain glass state at the low temperatures, rubber-elastic state at the elevated temperatures and transition state at the zone which the glass state change into the rubber-elastic state, can be discovered.

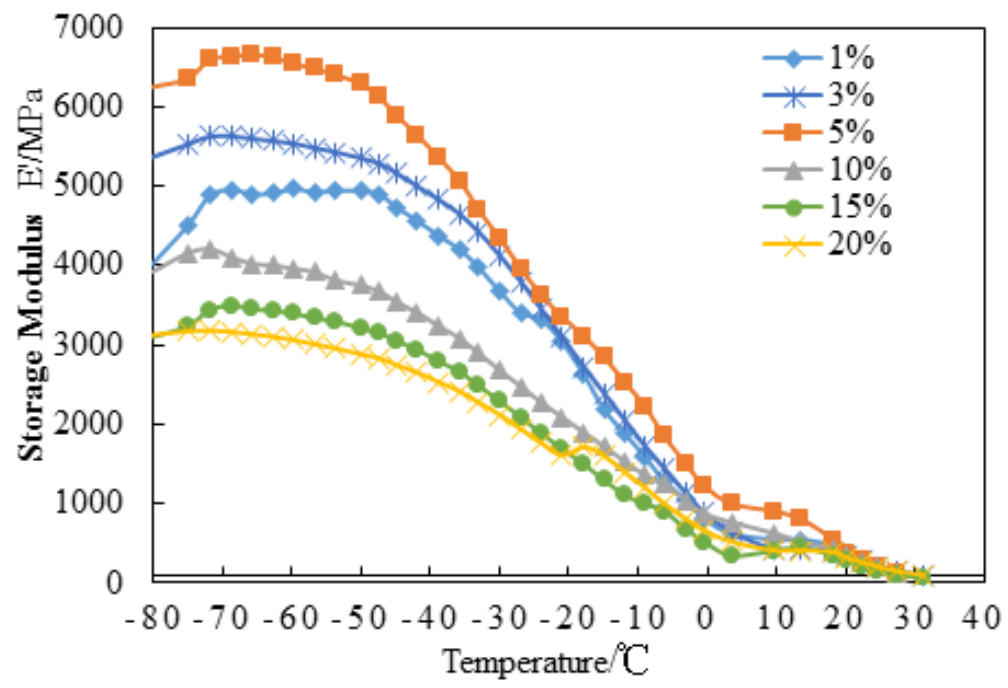

Fig. 1 Storage Modulus Curves

The relationship between storage modulus of different addition amounts of epoxy resin and temperature are basically the same in comparison with different addition amounts of epoxy resin. The storage modulus curve of EMB5wt\% show three kind of mechanical state; The storage modulus curve of EMB 10wt\% can't clear see the transition state; The transition state disappear when $20 \mathrm{wt} \%$ epoxy resin is added into base asphalt. Storage modulus reaches a maximum when 5 $w t \%$ epoxy is added to asphalt. When the epoxy resin is more than $5 \mathrm{wt} \%$, storage modulus decrease.

\subsection{Glass transition temperature of EMB}

The loss modulus E" represents the energy lose as heat because of the inner friction heating and is a measure of vibrational energy that has been converted during vibration and that cannot be recovered[12]. The loss modulus is used to assess the viscous properties of asphalt. The variation of loss modulus as a function of temperature of EMB is given in Fig.2. The curve of loss modulus have maximum value. The temperature corresponding to maximum loss modulus is glass transition temperature $\left(\mathrm{T}_{\mathrm{g}}\right)$. The loss modulus of EMB with different contents of epoxy resin have different maximum value and Tg[13]. Although, the storage modulus of EMB increases with the increase of temperature. Results showed that there is a temperature point, below this point, the modulus increased with the increase of temperature, over this point, it is on the contrary. The temperature of the maximum loss modulus is the glass transition temperature. The glass transition temperatures are seemingly irregular. The first glass transition temperatures of EMB1wt\%,EMB3 wt\%, EMB5 wt\%, 
EMB10 wt $\%$, EMB15 wt\%, and EMB20 wt $\%$ are $-21^{\circ} \mathrm{C},-15^{\circ} \mathrm{C},-27^{\circ} \mathrm{C},-4^{\circ} \mathrm{C},-24^{\circ} \mathrm{C}$, and $-15^{\circ} \mathrm{C}$, respectively.

The curve of loss modulus appears only one glass transition temperatures when $5 \mathrm{wt} \%$ and $10 \mathrm{wt} \%$ epoxy resin are added to base asphalt, which shows that EMB5 wt\% and EMB10 wt\% have good compatibility. The maximum loss modulus of EMB1 wt $\%$,EMB3 wt $\%$, and EMB5 wt\% reach 495MPa, while the maximum loss modulus of EMB10 wt\%,EMB15 wt\%, and EMB20 wt\% are below 255MPa. Under the same condition, the storage modulus and loss modulus change obviously as the contets of epoxy resin change, which indicate that additives have a great influence on the mechanical properties of EMB.

In addition, the curve indicated that the addtion of epoxy resin caused the loss modulus peaks to broaden and made the chain segments increase, which can restrain the relaxation process. When the epoxy resin more than $10 \mathrm{wt} \%$, the curve of loss modulus appear many peaks, which showed that addition of rubber powder and layered double hydroxides could cause the dispersion of EMB to be bad. The curve peak of loss modulus is narrow when $5 \mathrm{wt} \%$ epoxy resin is added to base asphalt. The narrow peak reflected the low dispersion degree of chain segments, which showed that chain segments is hard to relax. The curve peak values of loss modulus are high when the addition contents of epoxy resin is less than $10 \mathrm{wt} \%$, which means that the relaxation process need more energy.

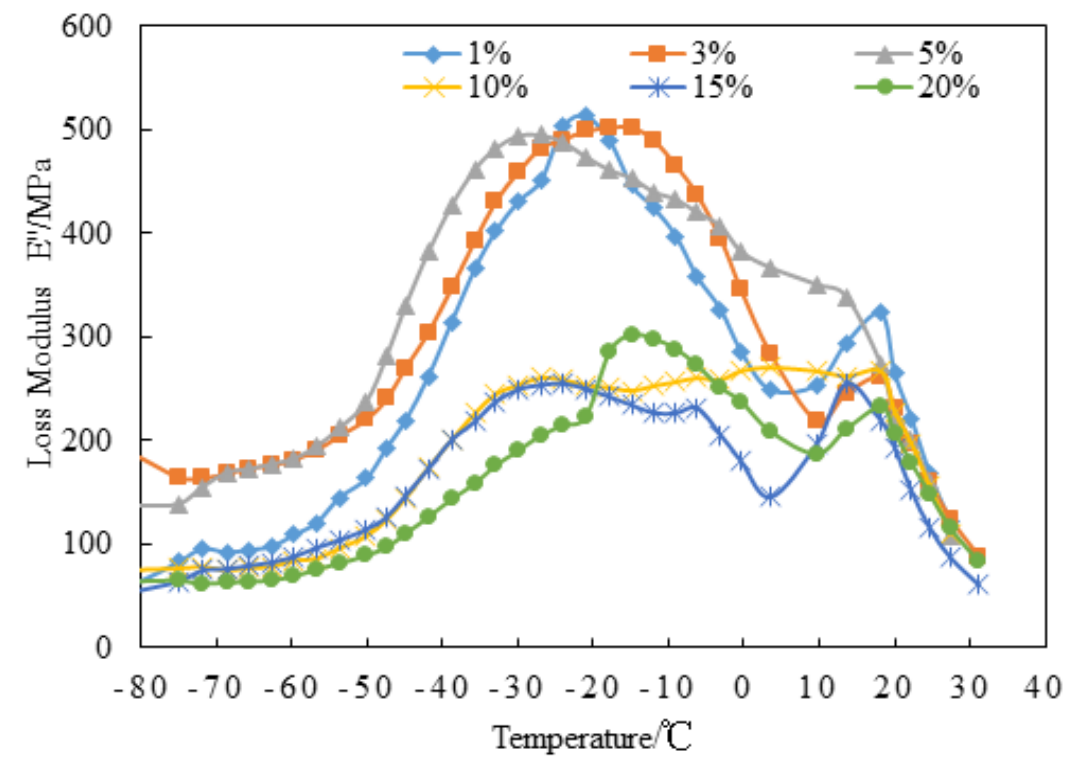

Fig 2. The curve of loss modulus

\subsection{Dynamic mechanical property of epoxy asphalt}

As shown in Fig.3, the dynamic modulus increase firstly and then decrease with the increase of contents of epoxy resin. However, the dynamic modulus will reach the maximum value when 5 wt $\%$ epoxy resin are added to base asphalt. The dynamic modulus increase slowly and then decrease quickly with the increase of temperature. Loss factor $(\tan \delta)$ values increase with the increase of temperature. When the epoxy resin is less than $10 \mathrm{wt} \%$, the dynamic modulus of EMB increase with the increase of the contents of epoxy resin. But the dynamic modulus of EMB remarkably decrease with the increase of the contents of epoxy resin, when the epoxy resin is more than $10 \mathrm{wt} \%$. 


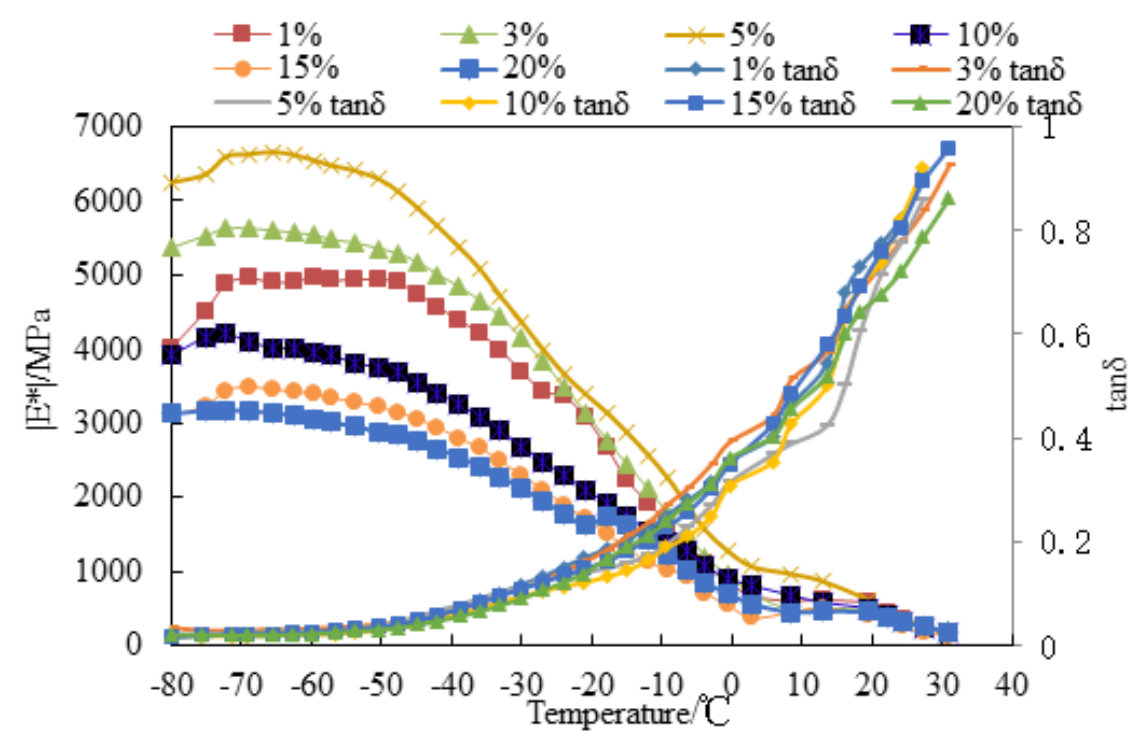

Fig 3. The curve of dynamic modulus and loss factor

\subsection{Frequency sweep}

EMB5 wt\% are chosen to conduct frequecy sweep at $20^{\circ} \mathrm{C}$ with a $5 \%$ strain control. In Fig.4, the dynamic modulus and storage modulus increase with the increase of load frequency, but loss factor is on the contrary. Results indicate that frequency has a great influence on dynamic modulus of EMB And the modulus of the high frequency are more than the modulus of the low frequency. This is, dynamic stiffness is more than static stiffness. Epoxy asphalt have good structural stability at high frequencies. It is of practical signification for the application.

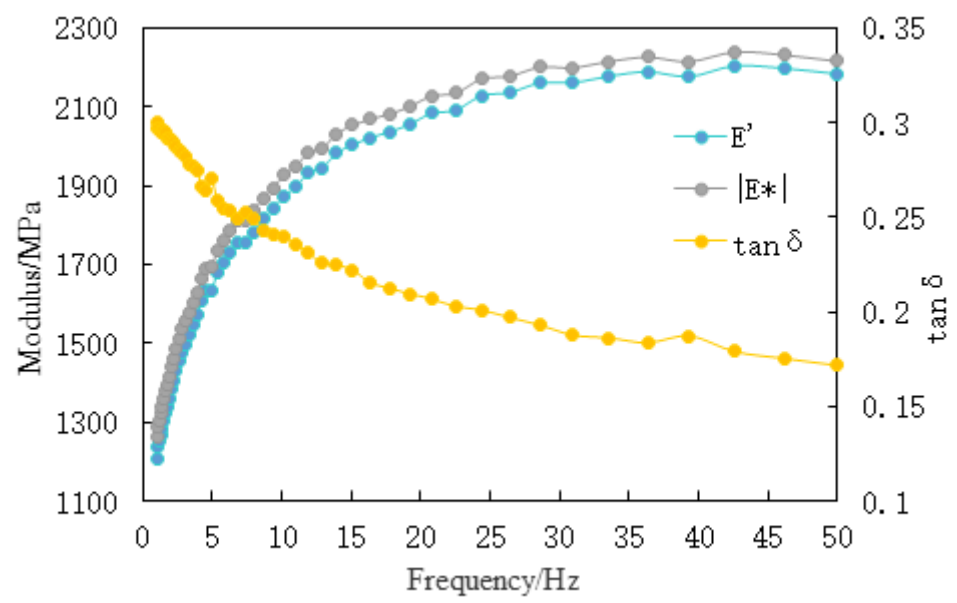

Fig 4. The curve of frequency sweep

\subsection{Microstructure analysis}

FM can easily observe the distribution conditionsof the additives in EMB at the curing process. There are basically two methods to prepare sample, press method and solvent method. As depicted in Fig. 5, we can see the morphology for epoxy asphalt $40 \times$ after curing 4 h. The images show a clear change in morphology of the EMB with the increase of the contents of epoxy resin. The black areas are asphalt, the grey-island areas are epoxy resin and the black spots in the grey-island areas are rubber particles[8]. When the epoxy resin is more than $10 \mathrm{wt} \%$, epoxy resin are more uniform than that in other images and cross-linking phases form a network structure which can enhance the properties of EMB. 


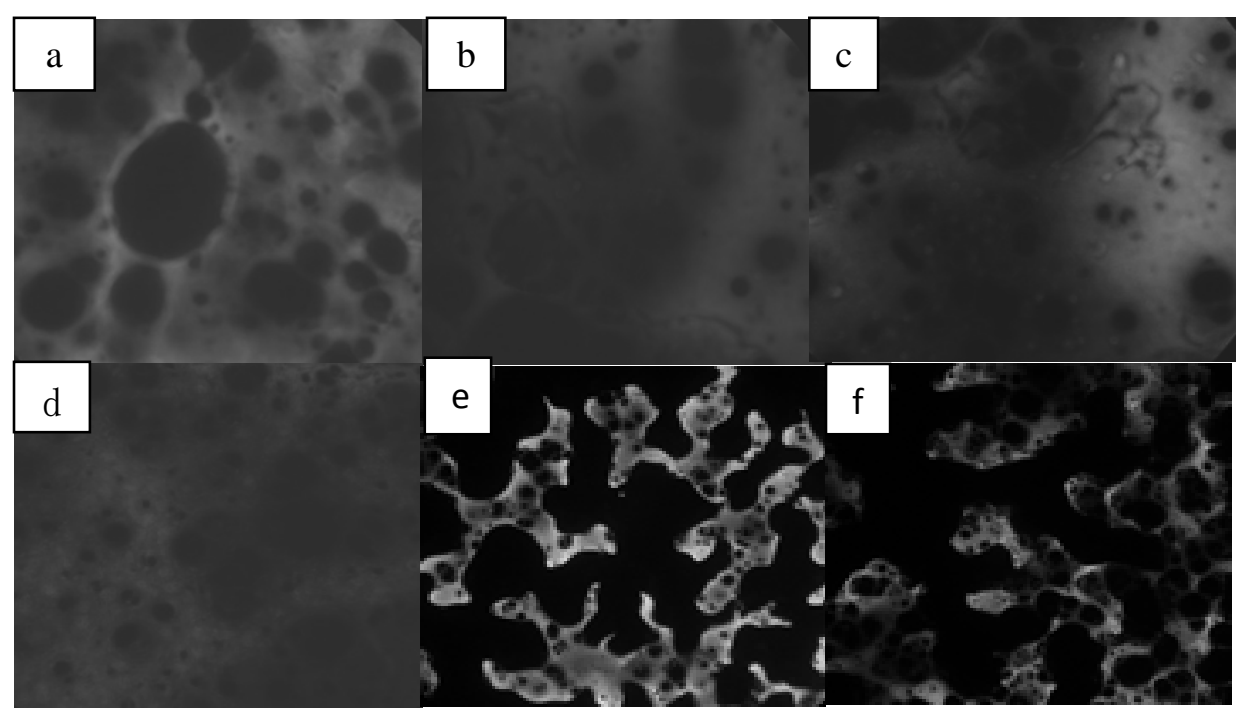

Fig.5 Morphology for EMB 40× after curing 4h: (a) EMB1wt\% ; (b)EMB3wt\%\% ;

(c) EMB5wt\% ; (d) EMB10wt\% ; (e) EMB15wt\% ; (f) EMB20wt\%

As shown in Fig.6, EMB samples were prepared by solvent method. In this method, the morphology of LDHs phase and rubber phase can be observed by fluorescent microscopy. LDHs and rubber phase is dispersed in the dark asphaltic phase in the form of almost spherical particles[14]. It is clear that there is on cross-linking between particles in EMB 1wt\%, which indicated that the consistency of asphalt with LDHs and rubber particles is poor. The adhesive force is very small between LDHs and rubber particles. Compared with EMB cured 0.5h, LDHs dispersed uniformly at the EMB 1wt\%. However, with the increase of the contents of epoxy resin, the epoxy resins form a networks. The dispersion of rubber is similar for LDHs. To better understand the effects of the curing time, EMB cured 4 h were also observed shown in Fig.7.a-f. Comparing the morphology of EMB cured 0.5h with 4 h, epoxy asphalt after the curing for 4 hours has basically finished the curing process and has formed the network structure. When the epoxy resin content is more than 3\%, the LDHs and rubber particles are distributed evenly in the epoxy asphalt, and form a stable continuous phase. Moreover, rubber particles become more and more smaller with the increase of the cured time.

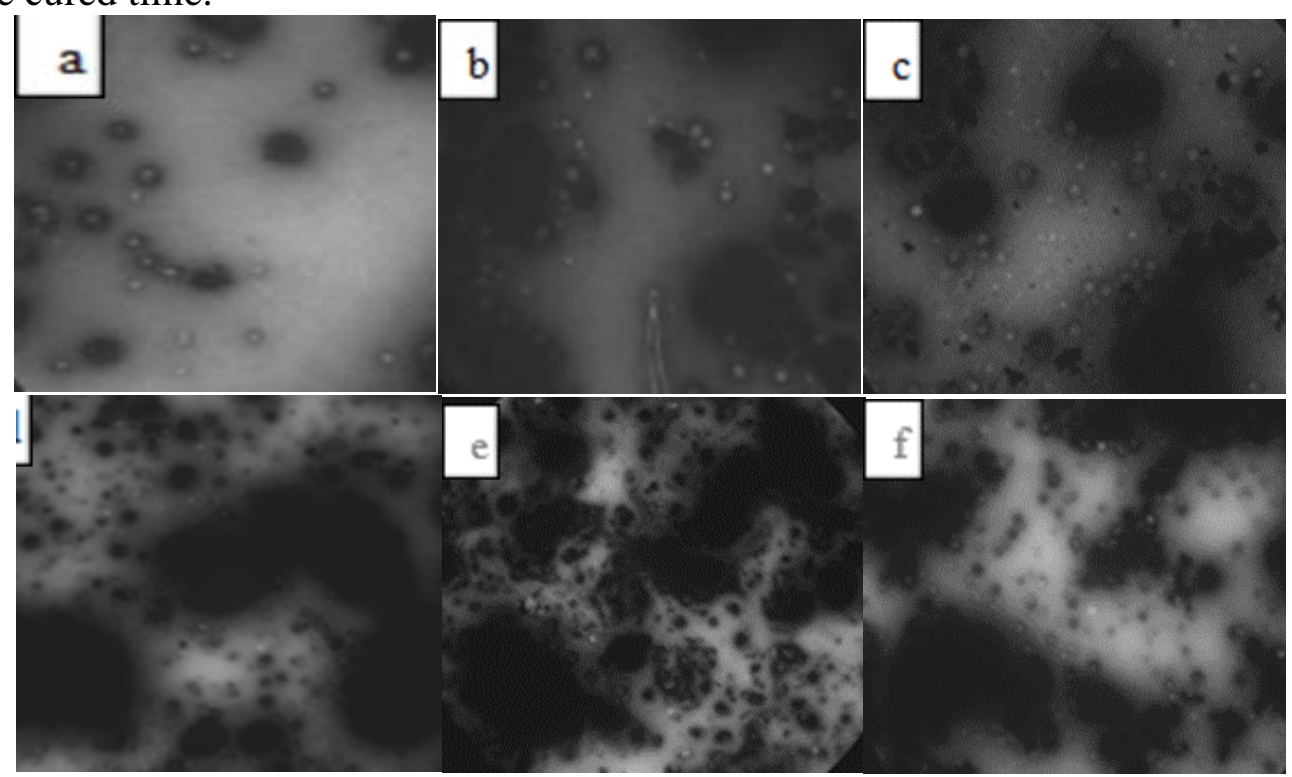

Fig.6 Morphology for EMB 40×: (a) EMB1wt\% and cured 0.5h; (b) EMB3wt\% and cured 0.5h; (c)

EMB5wt\% and cured 0.5h; (d) EMB10wt\% and cured 0.5h; (e) EMB15wt\% and cured 0.5h; (f)

EMB20wt\% and cured 0.5h; 


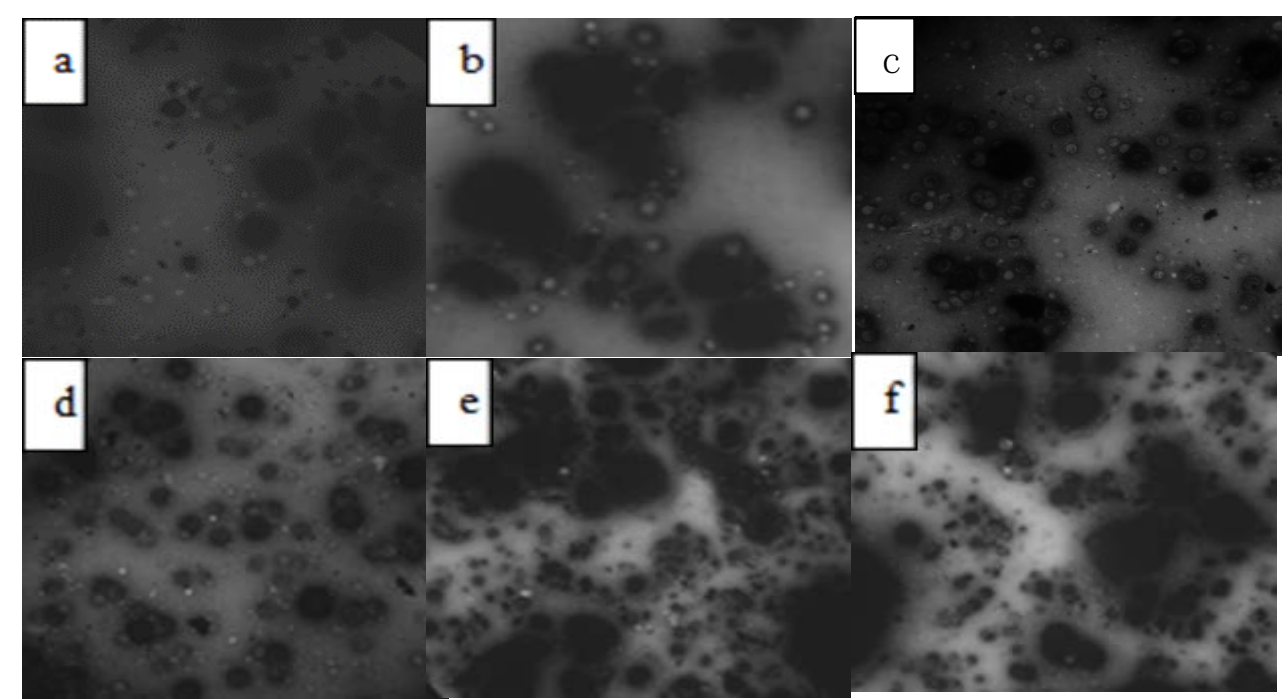

Fig.7 Morphology for EMB 40×: (a) EMB 1wt\% and cured 4h; (b) EMB 3wt\% and cured 4h; (c) EMB 5wt\% and cured 4h; (d) EMB 10wt\% and cured 4h; (e) EMB 15wt\% and cured 4h; (f) EMB 20wt\% and cured $4 \mathrm{~h}$.

\section{Conclusions}

(1) Epoxy resin can remarkably change storage modulus and loss modulus of EMB. Dynamic modulus of EMB reaches a maximum when the contents of epoxy resin are $5 \mathrm{wt} \%$. When the epoxy resin is more than 5\%, dynamic modulus and storage modulus of EMB decrease.

(2) FM analysis showed that EMB after the curing for 4 hours has basically finished the curing process and has formed the network structure. When the epoxy resin content is more than $3 \%$, the LDHs and rubber particles are distributed evenly in the EMB, and form a stable continuous phase.

\section{References}

[1] X. Ke, "Preparation and properties of epoxy modified asphalt," Wuhan University of Technology (2008).

[2] J. Jin, "Synthesis and characterization of novel self-curing epoxy resin," Beijing University of Chemical Technology (2011).

[3] J. Zhu, Z. Chen, Z. Min, W. Huang, and J. Wang, " Study on epoxy resin modified asphalt materials for highway," Journal of Southeast University (Natural Science Edition), vol. 34 (2004),p. 515-517.

[4] Cong, Peiliang, "Preparation and Properties of Epoxy Asphalt and it's Mixture [D]," Wuhan University of Technology (2009).

[5] Y. Xiao, M. van de Ven, A. Molenaar, Z. Su, and K. Chang, "Design approach for epoxy modified bitumen to be used in antiskid surfaces on asphalt pavement," Construction and Building Materials, vol. 41 (2013), p. 516-525.

[6] H. LV, X. ZHANG, R. ZHANG, and S. CHENG, "Preparation of modified asphalt with epoxy resin and rubber powder," New Building Materials, vol. 6 (2010),p. 006.

[7] M. Cubuk, M. Gürü, and M. K. Çubuk, "Improvement of bitumen performance with epoxy resin," Fuel, vol. 88 (2009), p. 1324-1328.

[8] X. Zhou, S. Wu, G. Liu, and P. Pan, "Molecular simulations and experimental evaluation on the curing of epoxy bitumen," Materials and Structures (2014), pp. 1-7.

[9] B. Brûlé, Y. Brion, and A. Tanguy, "Paving Asphalt Polymer Blends: Relationships between Composition, Structure and Properties (With Discussion)," in Association of Asphalt Paving Technologists Proc (1988).

[10] B. Sengoz and G. Isikyakar, "Analysis of styrene-butadiene-styrene polymer modified bitumen using fluorescent microscopy and conventional test methods," Journal of Hazardous 
Materials, vol. 150 (2008), p. 424-432.

[11] C. Ouyang, S. Wang, Y. Zhang, and Y. Zhang, "Thermo-rheological properties and storage stability of SEBS/kaolinite clay compound modified asphalts," European Polymer Journal, vol. 42 (2006), pp. 446-457.

[12] R. P. Chartoff, J. D. Menczel, and S. H. Dillman, "Dynamic mechanical analysis (DMA)," Thermal analysis of polymers: fundamentals and applications, (2009),p. 387-495.

[13] J. Guo, Z.h. Min, Z.j. Zhang, and D.l. Kong, "Dynamic mechanical property of epoxy resin asphalt in different crossing-density," Journal of Chang'an University (Natural Science Edition), vol. 6, (2011),p. 008.

[14] G. Polacco, S. Berlincioni, D. Biondi, J. Stastna, and L. Zanzotto, "Asphalt modification with different polyethylene-based polymers," European Polymer Journal, vol. 41 (2005), p. 2831-2844. 